\title{
A METHOD FOR COOLING RF WAVEGUIDES ON APT ${ }^{*}$
}

\author{
M. McCarthy and H. Yip ${ }^{\#}$, General Atomics, San Diego, CA \\ D. Rees and W. Roybal, LANL, Los Alamos, NM \\ J. Anderegg and S. Satpute, Burns \& Roe, Aiken, SC \\ D. McGuire and L. Toole, Westinghouse Savannah River Co., Aiken, SC
}

\begin{abstract}
The Accelerator Production of Tritium (APT) project will require up to $2441-\mathrm{MW}$ klystrons to provide radio frequency (RF) power for acceleration of a 100-mA proton beam. A major source of heat in the klystron gallery and the accelerator tunnel will be the RF waveguides, which conduct the RF power from the klystrons to the linac. Each waveguide is estimated to dissipate $11 \mathrm{~kW}$ of heat in the gallery and $17.5 \mathrm{~kW}$ in the tunnel. Base-case design called for conditioned-air cooling (to $104^{\circ} \mathrm{F}$ ) of the tunnel space, with waveguide cooling by forced external convection. For more uniform and efficient waveguide cooling, several other techniques have been investigated, including water-cooling, cooling by nitrogen purging, and direct cooling of the waveguides by using them as air conditioning "ducts." Models were created simulating the last technique. This paper will report on measurements to be made on the Low Energy Demonstration Accelerator (LEDA) at the Los Alamos National Laboratory (LANL) based on these models.
\end{abstract}

\section{INTRODUCTION}

The klystrons in the gallery output 1-MW of $700 \mathrm{MHz}$ RF power. The WR-1500 (15" x 7.5") rectangular, aluminum waveguide carries this power to ports on the linac. Because of the surface resistivity inside the aluminum waveguide, RF-induced currents generate heat. Calculations show that this frequency and magnitude of RF power through this size waveguide will generate 122 watts per linear foot. The surface resistivity of the waveguide rarely matches the ideal resistivity of the material. From empirical evidence, the actual power deposited in the guide is estimated to be about 250 watts per linear foot.

Experimental measurements at LANL's LEDA facility have shown the equilibrium temperature of an exposed waveguide is about $150^{\circ} \mathrm{F}$ for 6061 aluminum and $175^{\circ} \mathrm{F}$ for 5052 aluminum. In the klystron gallery, the temperature of the exposed waveguide must stay below $140^{\circ} \mathrm{F}$ for safety and technical reasons such as loss of efficiency, decrease in standoff voltage, and waveguide thermal expansion. Cooling the waveguide with internal air is an attractive alternative to water-cooling. The moving air inside the waveguide cools internal waveguide structures such as gas barriers and windows and can sweep away ions after an arc. Maintaining a positive pressure in the waveguide prevents the influx of contaminants. In addition, air exhausted from the waveguide may be used to cool the klystron garage, solenoids, dry loads, and planar windows.

\section{THEORY}

Under steady-state conditions, the heat generated in the waveguide wall is equal to the sum of heat transferred to the ambient air and to the heating, ventilation, and air conditioning (HVAC) air flowing inside the waveguide. A heat balance on a differential section of the waveguide wall yields the following equation for the surface:

$P_{W G} d x=h_{i}\left(T_{w}-T_{f}\right) l d x+h_{o}\left(T_{w}-T_{a}\right) l d x+h_{r}\left(T_{w}-T_{a}\right) l d x$

or

$$
T_{w}=\frac{P_{W G}+\left(h_{i}+h_{o}+h_{r}\right) l}{\left(h_{i}+h_{o}+h_{r}\right) l}
$$

where:

$h_{i}=$ heat transfer coefficient for internal waveguide surface, BTU/hr- $\mathrm{ft}^{2}-{ }^{\circ} \mathrm{F}$

$h_{o}=$ heat transfer coefficient for external waveguide surface, BTU/hr- $\mathrm{ft}^{2}-{ }^{\circ} \mathrm{F}$

$h_{r}=$ radiation heat transfer coefficient, BTU $/ \mathrm{hr}-\mathrm{ft}^{2}{ }^{\circ} \mathrm{F}$

$P_{W G}=$ power loss in waveguide walls per length, $\mathrm{W} / \mathrm{ft}$

$l=$ perimeter of waveguide cross-section, $\mathrm{ft}$

$T_{w}=$ waveguide surface temperature, ${ }^{\circ} \mathrm{F}$

$T_{a}=$ ambient air temperature, ${ }^{\circ} \mathrm{F}$

$T_{f}=$ temperature of HVAC air inside the waveguide, ${ }^{\circ} \mathrm{F}$

A heat balance on the HVAC air flowing inside the waveguide for the same differential section yields the following equation:

$$
m C_{p} \frac{d T_{f}}{d x}=h_{i} l\left(T_{w}-T_{f}\right)
$$

where:

$m$ = mass flow rate of HVAC air, $\mathrm{lb} / \mathrm{hr}$

$C_{p}=$ heat capacity of HVAC air, BTU/lb- ${ }^{\circ} \mathrm{F}$

These two equations were solved simultaneously to determine the required HVAC airflow rate to cool the waveguide surface to an acceptable temperature. Figure 1 shows the predicted waveguide surface temperature and

\footnotetext{
${ }^{*}$ Work supported by DOE under contract DE-AC04-96AL89607

\# E-mail: harry.yip@gat.com
} 
HVAC temperature as a function of waveguide length. The calculation was done for an airflow rate of $1,000 \mathrm{cfm}$ at $60^{\circ} \mathrm{F}$, a waveguide power loss factor of $250 \mathrm{~W} / \mathrm{ft}$, an internal surface heat transfer coefficient from DittusBoelter equation, and a weighted-average external surface transfer coefficient from correlations for vertical and horizontal flat plates. The calculation shows that the surface temperature is below $140^{\circ} \mathrm{F}$ at the exit of a $32-\mathrm{ft}$ long waveguide. Therefore, it is feasible to cool the waveguide with HVAC air.

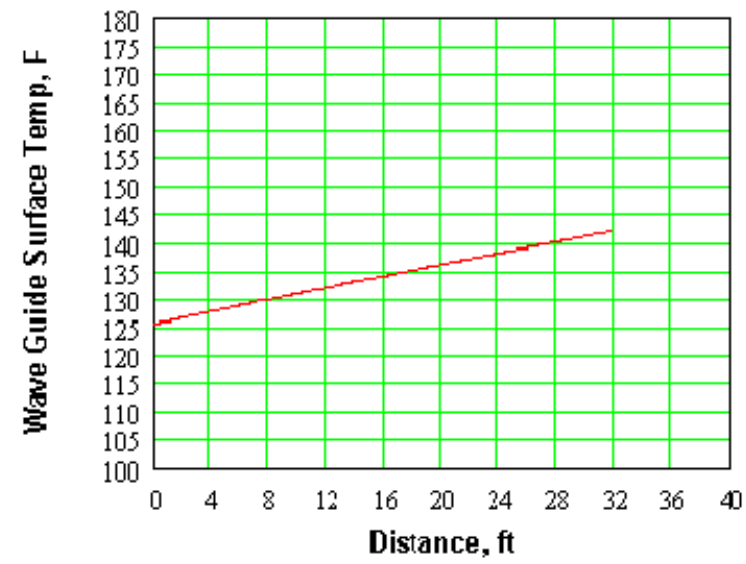

Figure 1: Predicted waveguide surface temperature

\section{EXPERIMENTAL CONFIGURATION}

The above calculations used approximate values for the power loss factor and heat transfer coefficients. An experimental program to determine these parameters is being carried out so that an accurate trade study may be conducted. Figure 2 shows the experimental configuration.

The device for determining the power loss factor is a water calorimeter, which consists of a 5-ft section of an actual waveguide wrapped with a 48-in. long water jacket. The jacket's annular gap is about 3/8-in. and it is subdivided into 6-in. wide flow channels so that water flows in a spiral pattern in the jacket. Water enters the jacket at one end through a manifold and exits at the other end. To prevent eddy air currents inside the waveguide, Teflon sheets are installed at the flanges before and after the test section. The external surface of the water jacket is insulated with a fiber blanket to minimize the free convection loss.

As the beam is conveyed through the guide, the water absorbs the heat due to power deposited in the walls. The amount of heat transferred is calculated from the measured water flow rate and temperature rise. The heat transferred divided by the waveguide water jacket length gives the power loss factor per unit length. The heat flux in $\mathrm{W} / \mathrm{ft}^{2}$ is obtained by dividing the heat transferred by the total surface area.

The apparatus for determining the internal convection heat transfer coefficients consists of from one to several 12-ft straight sections of waveguide with external insulation and two tees, one upstream and one downstream, for air inlet and outlet. The High Frequency Structural Simulation (HFSS) computer code was used to ensure no RF leakage for the air inlet and outlet boxes. Teflon sheets are used to block air convection between the test section and upstream and downstream waveguide sections.

Filtered air from a portable air conditioner or from a blower will be used for the experiments. By measuring the airflow rate, and the inlet and outlet air temperatures and relative humidity, the amount of heat transferred from the waveguide walls to the air can be calculated. The heat transfer coefficient is then calculated from the measured waveguide wall temperature and the surface area of the guide.

The apparatus for determining the external surface natural heat transfer coefficient is the same as that for the internal heat transfer coefficient except the thermal insulation is removed.

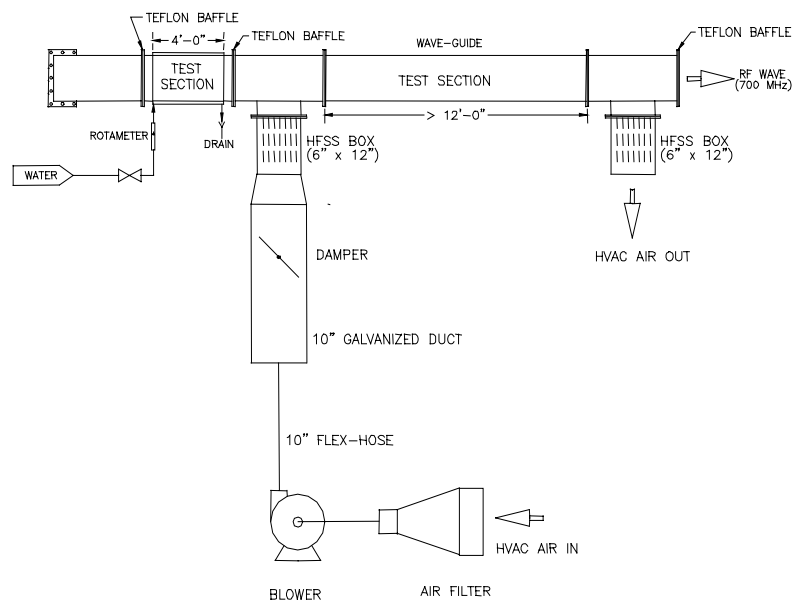

Figure 2: Experimental configuration

\section{EXPERIMENTAL PROCEDURES}

Waveguide power loss factor experiments will be performed for the following parameters:

- Water flow rate: $0.2 \mathrm{gpm}$ and $0.5 \mathrm{gpm}$

- Wave frequency: $700 \mathrm{MHz}$

- Waveguide: 15" x 7.5" rigid aluminum

- $\quad$ Power output: $1 \mathrm{MW}, 0.5 \mathrm{MW}, 0.25 \mathrm{MW}$

The internal heat transfer coefficient experiments will be performed for the following parameters:

- Airflow rate: 500 to $1500 \mathrm{cfm}$, in $250 \mathrm{cfm}$ increments

- $\quad$ Air inlet temp.: $\quad 55^{\circ} \mathrm{F} \& 65^{\circ} \mathrm{F}$ (room

temperature)

- Wave frequency: $700 \mathrm{MHz}$

- Power output: $1 \mathrm{MW}$

For each experiment, the airflow rate is adjusted to the desired rate. When steady state is reached, the inlet and outlet air dry-bulb and wet-bulb temperatures, waveguide surface temperature at various locations, and ambient temperatures are recorded. 
The heat transfer coefficient is calculated from a heat balance for each experiment. The coefficient, along with the physical properties of air, are then used to calculate the Nusselt, Reynolds, and Prandtl numbers. The Nusselt number is plotted against $\operatorname{Re}^{\mathrm{a}} \operatorname{Pr}^{\mathrm{b}}$ to obtain a correlation for predicting the heat transfer coefficient.

The external heat transfer experiments will be performed for all combinations of the following parameters:

$\begin{array}{lll}\text { - } & \text { Airflow rate: } & 0 \text {, and } 500 \text { to } 1500 \mathrm{cfm} \text { in } \\ & & 250 \mathrm{cfm} \text { increments } \\ \text { - } & \text { Air inlet temp.: } & 55^{\circ} \mathrm{F} \\ \text { - } & \text { Wave frequency: } & 700 \mathrm{MHz} \\ \text { - } & \text { Power output: } & 1 \mathrm{MW}\end{array}$

The experimentally-determined coefficient is the combined coefficient for natural convection and radiation.

\section{ANTICIPATED RESULTS}

Figure 3 shows the CCDTL Section 1 waveguide layout. The waveguide is subdivided within three areas: klystron gallery, under-berm conduit, and the tunnel. The total length of waveguide in the gallery is about $44-\mathrm{ft}$. The total length of the conduit is also $44-\mathrm{ft}$ of which $12-\mathrm{ft}$ is exposed and $32-\mathrm{ft}$ is in a concrete conduit. In the tunnel, the waveguide splits twice in the low-energy linac section. The total length is approximately $6.9-\mathrm{ft}$ for the first splitter and 13.8-ft for the second splitter. Whenever there is a split, the RF power loss factor also is reduced by half.

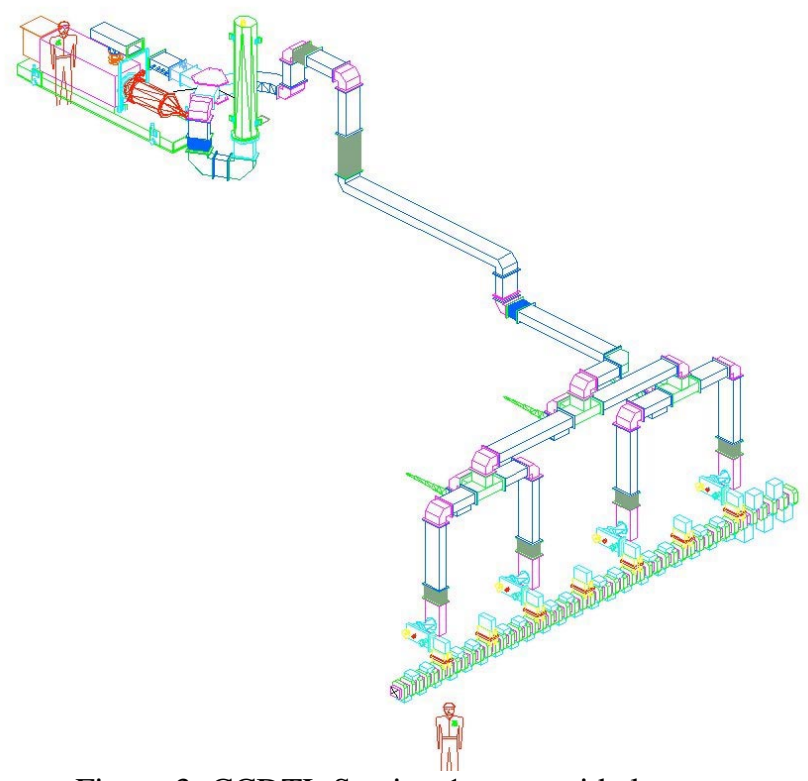

Figure 3: CCDTL Section 1 waveguide layout

Figure 4 shows the maximum waveguide surface temperature as a function of HVAC airflow. Table 1 shows predicted airflows required to maintain the coupled cavity drift tube linac (CCDTL) Section 1 waveguide below the $130^{\circ} \mathrm{F}$ maximum temperature.

\section{CONCLUSIONS AND RECOMMENDATIONS}

Test component design for the experimental set-up is currently in progress. The test results, when available, will be used to refine the heat transfer model used for the performance prediction.

Other techniques for cooling or reducing the heat produced by the waveguide include:

- $\quad$ Copper plate the waveguide inside surface to reduce the resistivity.

- $\quad$ Paint the outside surface of the waveguide with black high emissivity paint to enhance heat transfer by radiation.

- Increase the cross-sectional area of the guide.

- Air cool the outside of the guide by directing HVAC air on the guide.

- Water cool the outside of the guide with aluminum water channels brazed to the guide.

A trade study will compare the various techniques suggested in this paper. Life cycle costs, including capital equipment and operating and maintenance considerations, will be calculated and weighed against the perceived benefits of each approach. The final selection for cooling the RF waveguides on APT will emerge from the trade study as the lowest life cycle cost alternative that will meet the required availability and reliability criteria.

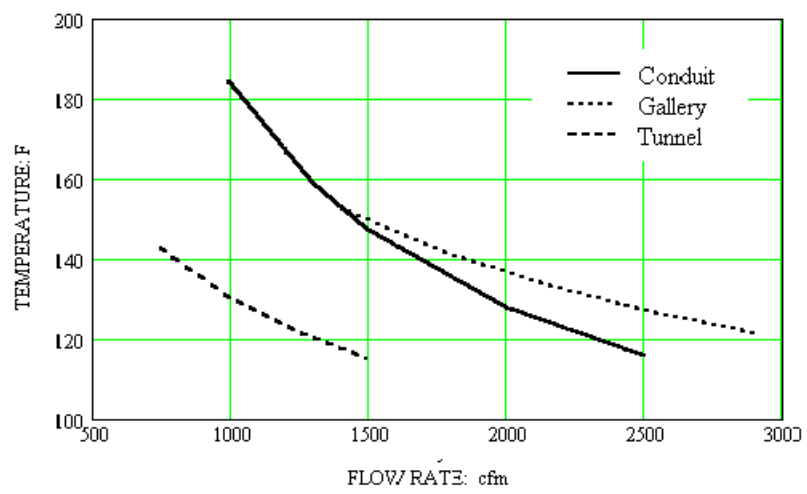

Figure 4: Maximum waveguide temperatures decrease with increasing airflow rate

Table 1: Predicted airflows to maintain CCDTL Section 1 waveguide temperatures below $130^{\circ} \mathrm{F}$

\begin{tabular}{|l|l|l|l|}
\hline & Gallery & Conduit & Tunnel \\
\hline Heat Removed, W & 10,975 & 11,000 & 6,400 \\
\hline Airflow, cfm & 2,250 & 1,950 & 1,000 \\
\hline Ambient Temp., ${ }^{\circ} \mathrm{F}$ & 90 & 104 & 104 \\
\hline Inlet Air Temp., $^{\circ} \mathrm{F}$ & 57 & 57 & 57 \\
\hline Outlet Air Temp., $^{\circ} \mathrm{F}$ & 74 & 81 & 79 \\
\hline
\end{tabular}

\section{ACKNOWLEDGEMENTS}

The authors would like to thank S.C. Yung, P. Davidson, T. Rosetta, and S. Wojtowicz for their design, performance predictions, and editorial contributions. 